\title{
The role of soil moisture initialization in subseasonal and seasonal streamflow prediction - A case study in Sri Lanka
}

\author{
Sarith P.P. Mahanama ${ }^{a, b, *}$, Randal D. Koster ${ }^{a}$, Rolf H. Reichle ${ }^{a, b}$, Lareef Zubair ${ }^{c}$ \\ a NASA Goddard Space Flight Center, Mail Stop 610.1, Global Modeling and Assimilation Office, Greenbelt, MD 20771, USA \\ ${ }^{\mathrm{b}}$ Goddard Earth Sciences and Technology Center, University of Maryland, Baltimore County, Baltimore, MD 21250, USA \\ ¿International Research Institute for Climate and Society, The Earth Institute at Columbia University, P.O. Box 1000, Palisades, NY 10964-8000, USA
}

\section{A R T I C L E I N F O}

\section{Article history:}

Received 12 February 2008

Received in revised form 16 June 2008

Accepted 18 June 2008

Available online 26 June 2008

\section{Keywords:}

Soil moisture

Soil moisture initialization

Streamflow

Streamflow prediction

Sri Lanka

\begin{abstract}
A B S T R A C T
The two main contributors to streamflow predictability at subseasonal to seasonal timescales in tropical regions are: (i) the predictability of meteorologic (particularly precipitation) anomalies, and (ii) the land surface soil moisture state at the start of the forecast period. Meteorological predictions at subseasonal timescale are usually fraught with error and may not be dependable. The accurate initialization of soil moisture, as obtained through real-time land data analysis, may provide skill in subseasonal to seasonal streamflow prediction, even when the prediction skill for rainfall is small.

A series of experiments using the Catchment Land Surface Model (CLSM) is performed to characterize the contribution of accurate soil moisture initialization to the skill of streamflow prediction in Sri Lanka at timescales up to 2 months. We find that at the monthly timescale, accurate soil moisture initialization provides between $10 \%$ and $60 \%$ of the total runoff prediction skill that could be obtained under a perfect prediction of meteorological forcing. Some contributions to streamflow forecast skill are also found for the second month of forecast.
\end{abstract}

(c) 2008 Elsevier Ltd. All rights reserved.

\section{Introduction}

Water is far from plentiful in many parts of the world, and regions with a tendency to experience water stress may reap important economic and societal benefits from water resources planning. If viable, a key aid to such planning would be accurate predictions of streamflow at subseasonal to seasonal timescales. Improved streamflow predictions would allow, for example, a more effective operation of reservoir systems.

Outside of mean seasonality, the two main contributors to streamflow predictability at subseasonal to seasonal timescales are [1-3]: (i) the predictability of meteorologic (particularly precipitation) anomalies, and (ii) the initialization of land moisture conditions at the start of the forecast period. Precipitation prediction has an obvious impact on streamflow prediction: greater rainfall implies greater streamflow. Furthermore, precipitation can indeed be predicted, at least to some extent, at seasonal leads, particularly in the tropics. Long-lead climate forecasts using coupled ocean-atmosphere-land models (e.g. [4]) are capable of predicting

\footnotetext{
* Corresponding author. Address: NASA Goddard Space Flight Center, Mail Stop 610.1, Global Modeling and Assimilation Office, Greenbelt, MD 20771, USA. Tel.: +1 301614 5667; fax: +1 3016146297.

E-mail addresses: Sarith.P.Mahanama@nasa.gov (S.P.P. Mahanama), Randal.D. Koster@nasa.gov (R.D. Koster), Rolf.H.Reichle@nasa.gov (R.H. Reichle), lareef@iri. columbia.edu (L. Zubair).
}

the state of the El-Nino Southern Oscillation (ENSO) months to seasons in advance. ENSO is well known for its impact on tropical rainfall [5] and exhibits a robust relationship with Sri Lankan rainfall and streamflow [6,7]. Evidence that ENSO can affect extratropical rainfall as well has also been reported $[8,9]$.

In the present paper, initialization of land moisture conditions translates to soil moisture and groundwater depth initialization, since we are focusing on the tropical region of Sri Lanka, for which snow storage plays no role. The role of initialized soil moisture on streamflow prediction is slightly more subtle than that of predicted precipitation. First consider that according to a number of observations-based studies, soil moisture memory may have a timescale of 1-3 months (e.g. $[13,14])$. Thus, the initial soil moisture provides some indication of the soil moisture state during the seasonal forecast period. Now consider that the wetness of the soil should exert some control over the runoff fraction (the ratio of the streamflow coming out of a watershed to the total rainfall incident on the watershed). Aside from special cases (e.g. the soil being so parched that it behaves like a "cement barrier" to infiltration), a wetter region will tend to convert a greater fraction of incident precipitation into runoff, and thus streamflow. In other words, if the surface is anomalously wet at the beginning of a forecast period, then even if the rainfall during the forecast period matches the multi-year mean for the period, one might predict anomalously high streamflow. Maurer and Lettenmaier [9] and Berg and Mulroy [10] have shown that the macroscale estimates of soil moisture indeed have 
the potential to enhance the streamflow prediction. The impact of the initial soil moisture state on hydrologic response at the catchment scale has also been noted $[11,12]$. Note that initial soil moisture can be determined through in situ observations or, perhaps more practically, through land data assimilation [15,16]. Accurate soil moisture initialization through land data assimilation has been shown to be viable for real-time monthly-to-seasonal forecast systems [17]. One aspect of land data assimilation involves driving a land surface model (LSM) over a region of interest with meteorological forcing derived from observations. In response to the observation-based forcings, the modeled soil moisture states (and implicit groundwater states) evolve to realistic values.

The contribution of soil moisture initialization to tropical streamflow prediction is examined here in the context of longterm observed and modeled hydrological datasets for the tropical island of Sri Lanka. Streamflow measurements in Sri Lanka at over 140 stations span a variety of climatic and geographic conditions (103 river basins that range from humid to semi-arid, from low to high altitudes, from 9 to $10,448 \mathrm{~km}^{2}$ in area) and extend from 1921 to the present [18]. Sri Lanka also offers an extensive historical precipitation record since 1869 with 400 functioning stations in an island of $65,000 \mathrm{~km}^{2}$. These precipitation records are of sufficient density to enable gridding at a resolution of $10 \mathrm{~km}$ [19]. These gridded data can be used in conjunction with bias-corrected global reanalysis data to force a state-of-the-art land surface model and thereby produce simulated streamflows for detailed analysis. The results should have direct relevance to water resources management in Sri Lanka and should also apply in a general sense to other regions that do not have snow cover.

Section 2.1 describes the Catchment Land Surface Model (the model used in this study), Section 2.2 describes the data used, and Section 3 describes the ability of this LSM to reproduce observed Sri Lankan streamflows when forced with realistic meteorological data. In subsequent sections, we describe the design of modified LSM simulations that isolate, quantify and compare the effects of accurate soil moisture initialization on streamflow prediction.

\section{Model and data used}

\subsection{The Catchment Land Surface Model (CLSM)}

Most LSMs coupled to Atmospheric General Circulation Models (AGCMs) effectively consider soil moisture to be uniform over a grid cell that may span hundreds of kilometers. Runoff generation and subsurface soil moisture movement in nature, however, are largely controlled by the topography of the land surface and spatial heterogeneity in soil moisture. Typical Soil Vegetation Atmosphere Transfer (SVAT) schemes are thus arguably ill-equipped to model runoff correctly (and, by extension, evaporation correctly [20]). Note also that imposing quasi-rectangular atmospheric grid elements on the land surface itself is a rather artificial representation, because in nature soil moisture movement and runoff generation take place over irregularly-shaped, topographically-defined hydrologic catchments (or watersheds).

These weaknesses in the standard SVAT representation prompted the development of the Catchment LSM (CLSM $[21,22])$. The CLSM considers irregularly-shaped hydrologic catchments as the fundamental elements of the land surface for computing land surface processes. Each catchment is partitioned into three regimes: (i) a saturated region, from which evaporation occurs with no water stress and over which rainfall is immediately converted to surface runoff, (ii) a sub-saturated region, from which transpiration occurs with no water stress and over which rainwater infiltrates the soil, and (iii) a "wilting" region, in which transpiration is shut off. The relative areas of these regions vary dynamically and are diagnostically computed from the model's three water prognostic variables and the topographic characteristics of the catchment. By continually partitioning the catchment into hydrologically distinct regimes and then applying different regime-appropriate physics within each regime, the CLSM should, at least in principle, provide a more realistic representation of land surface energy and water processes. The CLSM follows, as a matter of course, the state of shallow groundwater (down to about 2$3 \mathrm{~m}$ ); initialization of the CLSM thus includes an implicit initialization of shallow groundwater.

The model is designed to capture low frequency (monthly to seasonal) surface variability and has been evaluated successfully in a number of model intercomparison projects at the point, regional, and global scale [23-26]. Soil moisture memory associated with the model at the global scale has also been reported [27].

\subsection{Data sources}

For global scale studies with the CLSM, the Earth's land surface is first discretized into 36,716 hydrological catchments derived from high-resolution ( $1 \mathrm{~km}$ ) digital elevation data. The average size of these surface elements is $3800 \mathrm{~km}^{2}$. For technical reasons having do with coupling the CLSM to an Atmospheric General Circulation Model (AGCM), the regular atmospheric grid is then overlaid on top of the hydrological catchments, and catchments found to straddle adjacent grid cells are separated into independent surface elements, one inside each grid cell. Of particular relevance here, Sri Lanka is divided into 18 catchments that are further sub-divided (by the overlaid $0.25^{\circ}$ atmospheric grid) into 165 tiles - the basic modeling units for this study. Model parameters were derived from a variety of state-of-the-art global datasets: vegetation classification was based on $1 \mathrm{~km}$ land cover characteristics [28], and soil texture classification came from $5^{\prime} \times 5^{\prime}$ global maps [29].

Berg et al. [30] merged output from the European Center for Medium-Range Weather Forecast (ECMWF) global reanalysis (ERA-15) with observed surface meteorological fields (precipitation, radiation and temperature) to produce a global, $0.5^{\circ}, 6$-hourly forcing dataset for the period 1979-1993. The processed data include precipitation, shortwave and longwave radiation, wind, surface pressure, specific humidity, and $2 \mathrm{~m}$ air temperature. For the current study, monthly rainfall measurements from 287 Sri Lankan stations (gray dots in Fig. 1b), gridded to a resolution of $0.25^{\circ}$, were used for the spatial downscaling and additional bias-correction of the precipitation component of the Berg data. The downscaled, bias-corrected data were used to force the 165 catchment tiles in Sri Lanka over 1979-1993. Simulated streamflow production was compared to monthly streamflow observations at 22 sites obtained from the Sri Lanka Department of Irrigation and Mahaweli Authority of Sri Lanka (Fig. 1b and Table 1). These 22 stations were selected from 140 stations with long records based on the completeness of their records, their ability to represent different climate regimes on the island, and the minimal impact of reservoir operation on the station data. Occasionally, for some stations, data for particular months are missing.

We use model-based estimates for the soil moisture initialization, as well. Direct measurements of soil moisture are still lacking in many parts of the world, particularly outside parts of Asia and North America. Certain instruments aboard Earth-orbiting satellites (past, current, and planned) can provide soil moisture estimates at various temporal and spatial timescales, but only down to a few centimeters in depth at most, and generally not in regions of dense vegetation. Therefore, we estimate soil moisture by forcing CLSM with observations-based meteorological forcing, as described above. This general approach, popular in recent years [15,31-33], provides soil moisture estimates that reflect an integration of antecedent meteorological forcing, using physically- 

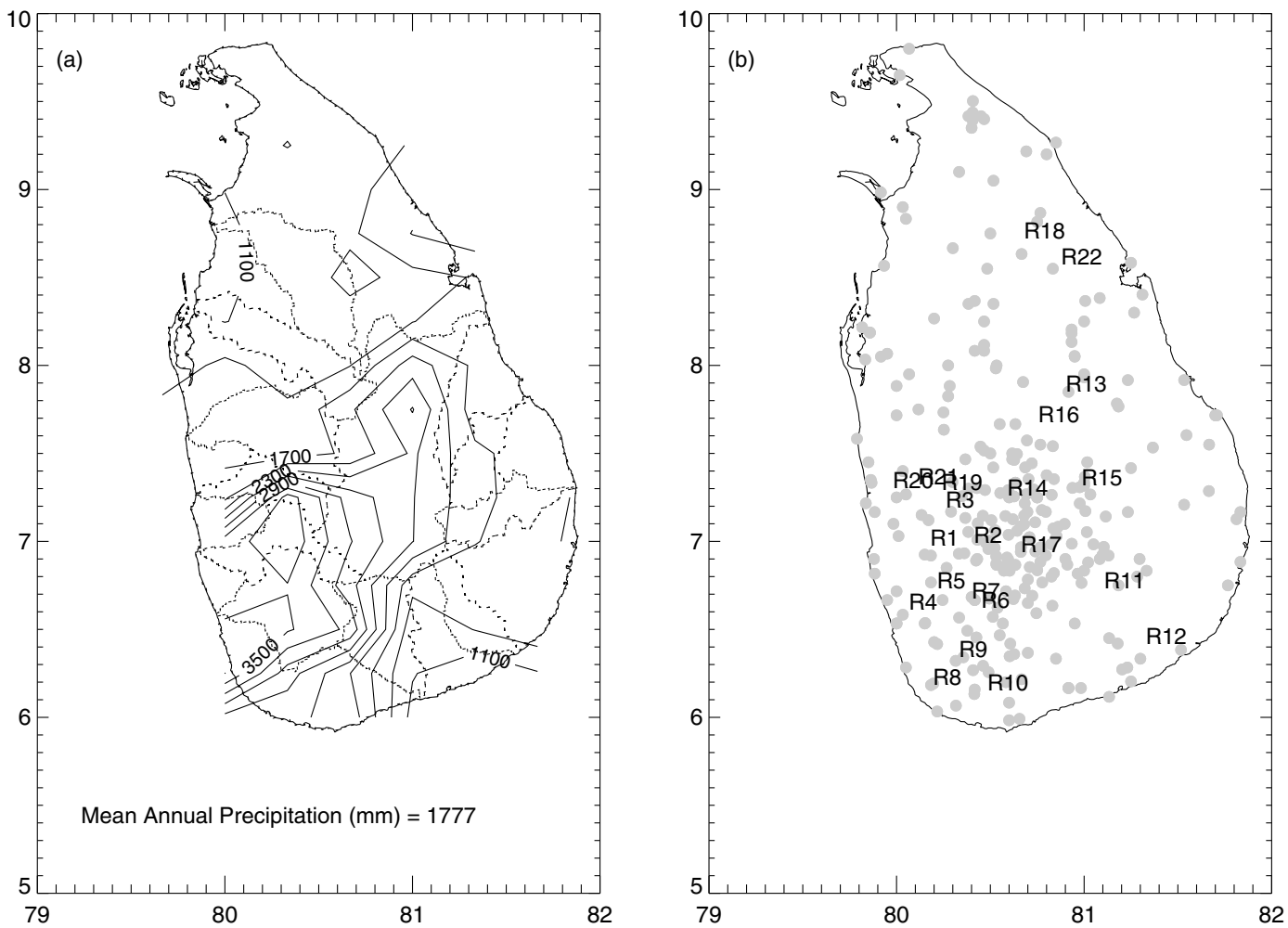

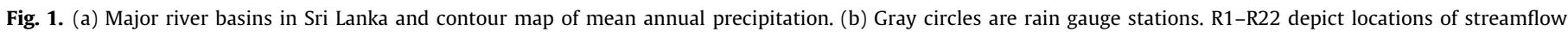
measurement stations (Table 1 ).

based representations of hydrological processes. A relatively rainy March and April, for example, will produce an appropriately relatively wet soil moisture initial condition for the first of May.

\section{Performance of the model}

The streamflows generated by CLSM when forced with the observations-based meteorological data (the "CTRL" experiment, see Table 2) are compared with streamflow measurements at 22 stations that span a variety of climatic and topographic conditions (Fig. 1b, Table 1). The observed streamflows were normalized by

Table 1

Details of streamflow measuring stations

\begin{tabular}{|c|c|c|c|c|}
\hline \multirow[t]{2}{*}{ Station } & \multicolumn{2}{|l|}{ Location } & \multicolumn{2}{|l|}{ Catchment } \\
\hline & Latitide (N) & Longitude (E) & Elevation (m) & Area $\left(\mathrm{km}^{2}\right)$ \\
\hline Glencourse (R1) & 6.974 & 80.180 & 18 & 1463 \\
\hline Kitulgala (R2) & 6.991 & 80.412 & 56 & 388 \\
\hline Holombowa (R3) & 7.193 & 80.262 & 53 & 155 \\
\hline Putupaula (R4) & 6.611 & 80.065 & 2 & 2598. \\
\hline Ellagawa (R5) & 6.731 & 80.216 & 4 & 1393. \\
\hline Dela (R6) & 6.622 & 80.452 & 29 & 220. \\
\hline Ratnapura (R7) & 6.675 & 80.400 & 14 & 604 \\
\hline Agaliya (R8) & 6.187 & 80.195 & 10 & 696 \\
\hline Jesmin Dam (R9) & 6.344 & 80.333 & 27 & 361 \\
\hline Bopagoda (R10) & 6.155 & 80.484 & 18 & 442 \\
\hline Wellawaya (R11) & 6.731 & 81.106 & 154 & 160 \\
\hline Kataragama (R12) & 6.419 & 81.329 & 34 & 787 \\
\hline Angamedilla (R13) & 7.849 & 80.902 & 67 & 1363 \\
\hline Peradeniya (R14) & 7.258 & 80.590 & 463 & 1167 \\
\hline Weragantota (R15) & 7.316 & 80.986 & 76 & 4092 \\
\hline Elahera (R16) & 7.679 & 80.756 & 133 & 774 \\
\hline Talawakelle (R17) & 6.940 & 80.662 & 1200 & 297 \\
\hline Yakawewa (R18) & 8.723 & 80.680 & 70 & 110 \\
\hline Alawwa (R19) & 7.291 & 80.240 & 49 & 804 \\
\hline Badalgama (R20) & 7.302 & 79.980 & 12 & 1360 \\
\hline Girialla (R21) & 7.324 & 80.115 & 27 & 1191 \\
\hline Horowapotana (R22) & 8.576 & 80.878 & 44 & 942 \\
\hline
\end{tabular}

catchment area; both observed and simulated streamflows are thus expressed in units of $\mathrm{mm} / \mathrm{month}$.

Figs. 2 and 3 compare the monthly time series of simulated and observed runoff for the 22 stations. The simulations and the observations are in reasonable agreement at most of the stations. When the comparison is weak, a closer look at the observed $0.25^{\circ}$ monthly precipitation time series shows (in most cases) that the precipitation data seem to be inconsistent with the independent streamflow measurements at the station. This may be due to known weaknesses in the observations of large flows (e.g. Putupaula 1987-1988, Alawwa (1979, 1990-1991)), and there may be drifts in the calibration of the observing system, as at Agaliya from 1989 to 1991. Additional differences between the observed and simulated values, for all stations, may stem from the scale disparity between the ECMWF reanalysis forcings and local catchments and, of course, from deficiencies in the model's physical formulations.

For our subsequent analyses, we accept the fact that at some stations, the CLSM products do not, either due to model or observational error, match the observations well. We in fact focus our analyses on those eight stations for which the temporal $r^{2}$

Table 2

Experiment details: see text for a comprehensive description

\begin{tabular}{ll}
\hline $\begin{array}{l}\text { Exp. } \\
\text { name }\end{array}$ & Experiment details \\
\hline CTRL & $\begin{array}{l}\text { Perfectly predicted meteorological forcings with perfectly initialized } \\
\text { soil moisture } \\
\text { Prescribed mean seasonal cycles of the observed forcings with } \\
\text { initialized soil moisture at the beginning of 2-month forecast }\end{array}$ \\
FC-WI & $\begin{array}{l}\text { Same as FC-WI but (re-)initializing soil moisture every day } \\
\text { FC-W01 }\end{array}$ \\
FC-W05 & $\begin{array}{l}\text { Same as FC-W01 but (re-)initializing soil moisture every 5 days } \\
\text { FC-W10 }\end{array}$ \\
FC-WC & $\begin{array}{l}\text { Prescribed mean seasonal cycles of the observed forcings with no } \\
\text { knowledge of initial soil moisture conditions }\end{array}$ \\
\hline
\end{tabular}




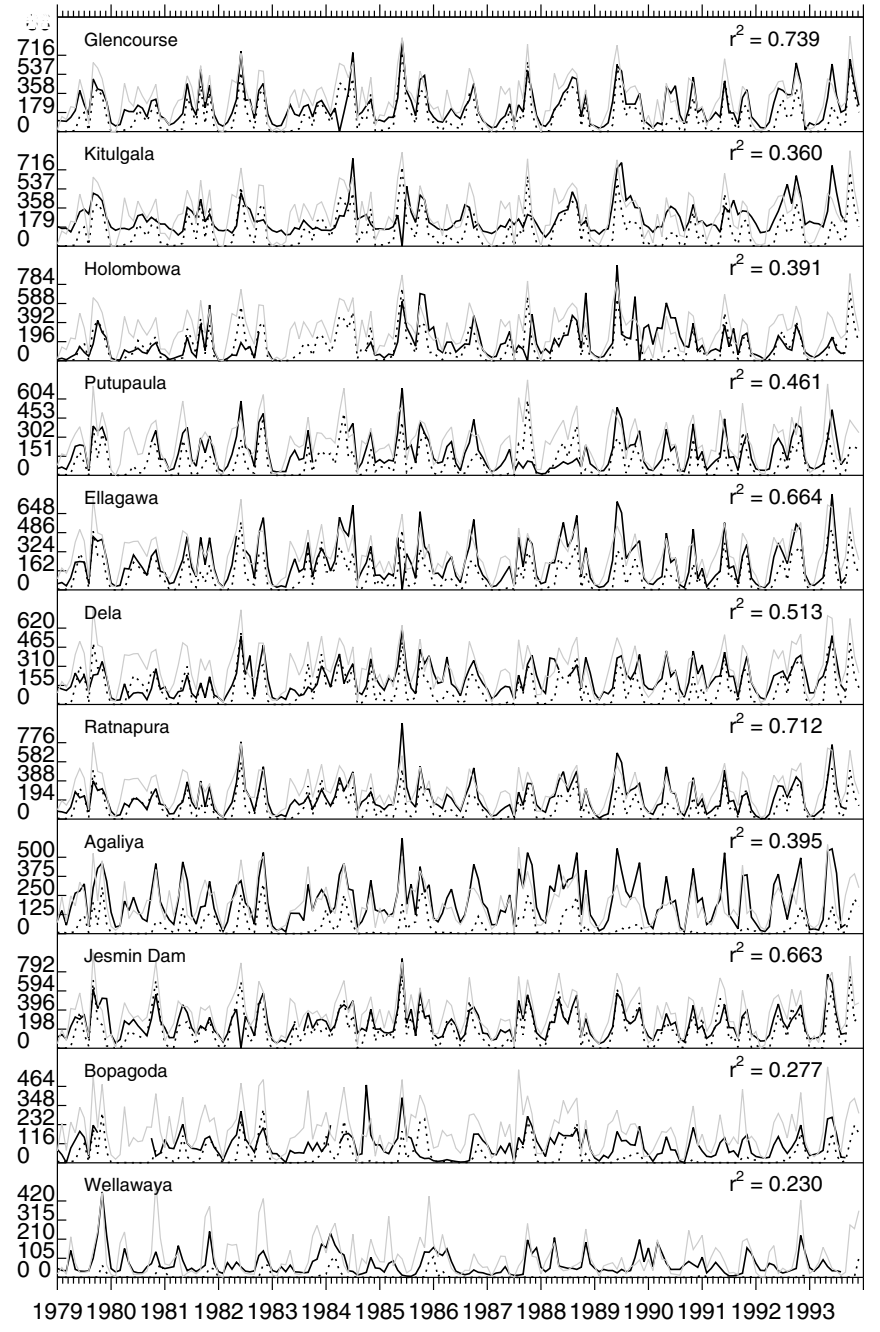

Fig. 2. Monthly streamflow comparison for stations R1-R11. Dark solid line: observed monthly mean streamflow in $\mathrm{mm}$ (normalized by catchment area). Dashed line: simulated monthly mean total runoff ( $\mathrm{mm}$ ). Gray line: monthly mean precipitation in $\mathrm{mm}$ (from forcings). The $r^{2}$ values are shown in the panels.

values between observed and simulated monthly streamflow are higher than 0.66 - that is, where the combination of model physics and available forcing data together explain two-thirds or more of the observed streamflow variance. After all, our goal from here on is not to validate the CLSM but rather to use it in controlled studies to determine the source of any streamflow prediction skill that does exist in the model. (Note that our skill diagnostic focuses on the ability of the model to reproduce streamflow variations in the time rather than long-term means. For forecasting, prediction of variations is key; presumably model biases in the mean can be scaled away. Figs. 2 and 3 show that some large biases in the long-term mean streamflow simulation do exist at some catchments.) We note that our analyses were also performed at the other stations, and though the results at these stations are somewhat noisier, they essentially agree with those described below. The eight stations that were chosen include two stations (Peradeniya and Glencourse) that are affected by flow modifications due to construction of reservoirs, but these influences are modest [7].

\section{Experiment design}

We assume here that, regardless of lead time, skill in streamflow forecasting in non-snow areas has three potential sources:

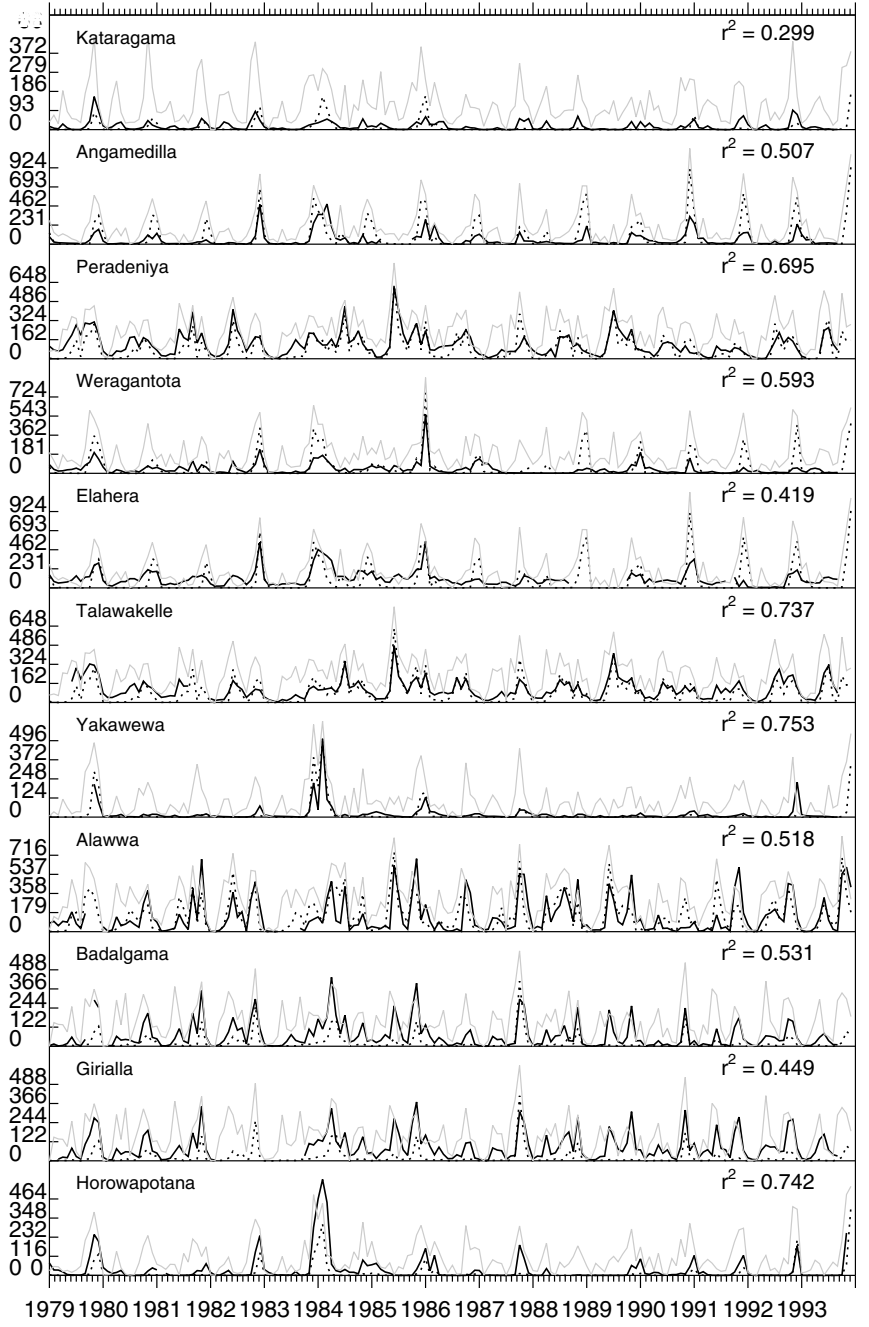

Fig. 3. Same as Fig. 2, but for stations R12-R22.

(i) the accurate prediction of forcing anomalies (mainly, precipitation) during the forecast period, (ii) knowledge of soil moisture anomalies at the beginning of the forecast period, which determines the 'preconditioning' of the soil to the generation of large runoff efficiencies, and (iii) the underlying mean seasonal cycle of streamflow (some months typically have more streamflow than others), which mainly reflects the mean seasonal cycles of the precipitation and radiation forcing in the region. Our goal in this section is to design experiments that isolate the second contribution to streamflow forecast skill.

The contribution of the third (mean seasonality) source is quantified by repeating the simulations underlying Figs. 2 and 3 with two restrictions: a complete lack of knowledge of forcing anomalies, and a complete lack of information regarding soil moisture anomaly initialization. These restrictions are imposed by forcing the model with the mean seasonal cycle of the observed forcing (precipitation, radiation, etc.) as derived from the multiple years of forcing used for CTRL, and by resetting soil moisture every day to its climatological value for that time of year as determined from the output of the 15-year CTRL experiment. This experiment is referred to below as FC-WC, shorthand for "forcing climatology, wetness (soil moisture) climatology". Simply put, this experiment provides streamflow "predictions" drawn from the climatological seasonal cycle of streamflow at the station as produced by the model - predictions reflecting solely the mean seasonal cycles of forcing and soil moisture in the basin. Consecutive 2-month sub- 
sets of the single FC-WC simulation for each watershed are interpreted as individual 2-month forecasts, forecasts made in the absence of any information on forcing anomalies or soil moisture anomalies.

In a second set of simulations, the mean seasonal cycles of the observed forcing are imposed (as in FC-WC) but the soil moisture is reset to its value from CTRL at the beginning of each 2-month forecast period. In essence, the CTRL experiment here is used as an offline land data assimilation system for generating realistic initial soil moistures, a system of the type that can be run in real-time as part of a true, operational forecast system [15]. At each of the eight watersheds considered, a series of 2-month forecasts are performed starting on the first day of each month in the 15-year period. We refer to this set as FC-WI, short for "forcing climatology, wetness (soil moisture) initialized". For the months following the soil moisture initialization, simulated streamflows have only two sources of skill: the initialization and the mean seasonality of streamflow, as in FC-WC. The forecasts in FC-WC gain no skill whatsoever from the accurate prediction of forcing anomalies (rainfall, etc.).

For context, we interpret CTRL as a third set of "forecasts" each consecutive 2-month subset of CTRL is considered a forecast in which the soil moisture is initialized accurately (as in FC-WI) and all of the meteorological forcing during the forecast period is predicted perfectly, at all timescales. (Note that "perfect" here does not mean error-free; the forcing used may indeed fraught with errors. By "perfect", we mean that the forcing is predicted correctly to within the accuracy of measurements during the forecast period.) Consequently, the CTRL forecasts derive skill from knowledge of soil moisture initialization, and knowledge of forcing during the forecast period. CTRL thus provides the upper limit to the forecast skill achievable by the model from all three sources. Such skill will never, of course, be reached in practice due to significant, inherent limitations imposed by nature (chaos) in our ability to predict the forcing.

We process the results as follows. As before, we use the $r^{2}$ value between the streamflows produced by each simulation and the monthly observations to characterize forecast skill. The contribution of realistic soil moisture initialization to streamflow forecast skill is thus the skill from FC-WI above the baseline skill from FC-WC, i.e., $r_{\mathrm{FCWI}}^{2}-r_{\mathrm{FCWC}}^{2}$. Similarly, the combined contribution of realistic soil moisture initialization and a perfect prediction of forcing to the streamflow forecast skill is $r_{\mathrm{CTRL}}^{2}-r_{\mathrm{FCWC}}^{2}$. We compute the diagnostic $\alpha$ as

$\alpha=\frac{r_{\mathrm{FCWI}}^{2}-r_{\mathrm{FCWC}}^{2}}{r_{\mathrm{CTRL}}^{2}-r_{\mathrm{FCWC}}^{2}}$

and interpret $\alpha$ as the fraction of the maximum possible skill that could be achieved (over the baseline skill, from FC-WC) that stems from soil moisture initialization alone. Again, $r_{\mathrm{CTRL}}^{2}-r_{\mathrm{FCWC}}^{2}$ is an overestimate of this maximum possible skill, since chaos prevents such a perfect prediction of forcing. As a result, $\alpha$ is indeed a lower bound for the relative contribution of soil moisture initialization to forecast skill.

\section{Results: impact of initial soil moisture state}

\subsection{Monthly forecasts}

Results for the two-month forecast are shown in Fig. 4. The first histogram bar in each panel shows $r_{\text {CTRL }}^{2}$, the skill level for CTRL. The final histogram bar shows $r_{\mathrm{FCWC}}^{2}$, the minimum baseline skill level associated with seasonality. The second histogram bar shows the skill levels for 30-day streamflow forecasts under realistic soil moisture initialization and climatological forcing, $r_{\mathrm{FCWl}}^{2}$. The value of $\alpha$ for the watershed is provided inside each panel. The panels are ordered in terms of the skill found in CTRL, with the basin showing the most skill presented first.

For the first month of forecast, the values of $\alpha$ for the eight basins range from about 0.1 to 0.6 . In other words, even if a forecast system could provide perfect predictions of forcing throughout the forecast period, a significant fraction of the forecast skill would nevertheless come from the soil moisture initialization alone. Fig. 4 indeed reveals the main result of this paper: realistic soil moisture initialization, an achievable element of today's forecast systems, can provide useful information on future streamflow volumes, information that can be of relevance to water resources management. Given that forcing predictions can never be perfect, the true relative contributions of "perfect" soil moisture initialization to total achievable skill must be higher still - perhaps significantly higher.

The third histogram bar in Fig. 4 shows the skill level for the second month of forecast. These skill levels are, as expected, lower than those for the first month, simply because initialization has a reduced impact as one moves farther away from the forecast start date. In fact, for the first three watersheds, soil moisture initialization appears to provide no skill whatsoever to streamflow prediction in the second month. Even so, for the remaining five watersheds, the alpha values range from 0.1 to 0.3 . In other words, for these latter watersheds, the CLSM appears to capture soil moisture memory adequately enough to allow the initial soil moisture conditions to provide some skill to streamflow prediction at this longer lead. Note that for the second forecast month, atmospheric initialization (the key to rainfall prediction at synoptic timescales) should play no role in runoff production (aside from its impact on soil moisture in the first week or so of the forecast), suggesting that the values shown for CTRL are indeed much higher than those that could be achieved with a standard forecast system. The relative importance of soil moisture initialization to total achievable skill at 2 months is thus probably much higher than suggested by Fig. 4 .

\subsection{Seasonality of initialization's contribution}

The significant climatic processes that bring rainfall to Sri Lanka are the inter-tropical convergence zone (April-June, OctoberNovember), the easterly jet (July and August), the monsoon (October-December), and orographic rainfall in the western hill slopes (May-September) and eastern hill slopes (December-February) $[34,7]$. No clear-cut method is thus available for specifying seasons in Sri Lanka. For our analysis, we will consider January-March (JFM) and July-September (JAS) as inter-monsoon periods and April-June (AMJ) and October-December (OND) as monsoon periods, in rough agreement with conventional definitions.

Fig. 5 shows a repeat of Fig. 4 (but showing only the skill level for the first month of forecast), with the results broken down by monsoon and inter-monsoon period. A distinction is seen between the results for Yakawewa (R18) and Horowapotana (R22) and those for the remaining six considered watersheds: for Yakawewa and Horowapotana, soil moisture initialization contributes much more to streamflow prediction skill during inter-monsoon seasons, whereas for the other six watersheds, it contributes significantly more during monsoon seasons. This distinction is interesting because the first two watersheds are physically removed from the other six. The first two lie in the northern, drier part of the island, and the other six lie in the much wetter southwestern part of the island. Naturally, the limited nature of this study prevents firm conclusions regarding such distinctions. Still, based on Fig. 5, we can speculate that for wetter areas, land moisture initialization is more important during monsoon periods, and for drier areas, it is more important during inter-monsoon periods. 


\subsection{Inferences regarding prediction at shorter timescales}

Streamflow prediction at timescales shorter than a month cannot be analyzed directly in this study because the streamflow validation data are available only in the form of monthly totals. Nevertheless, useful inferences regarding prediction at shorter leads can be made through a simple summing procedure. We proceed as follows. We repeat the forecast simulations comprising FCWI, except now, instead of running 2-month forecasts with the climatological forcing, we run $N$-day forecasts $(N=1,5,10$, with experiments labeled FC-W01, FC-W05, and FC-W10, respectively) with the climatological forcing, each forecast initialized with the appropriate value from CTRL (CTRL output is available for each day of the 15-year period.). For example, for June of 1980, six 5day forecasts are performed. They are initialized on June 1, 6, 11, 16,21 , and 26 with the CTRL values for those dates, and they produce six 5-day streamflow predictions. The six 5-day predictions are summed to a monthly total that is compared to the observed monthly total for June of 1980 .

Fig. 6 shows the results. As before, by the design of the analysis (we are comparing to observed monthly streamflows), the histogram bars for CTRL and FC-WC are identical to those in Fig. 4.
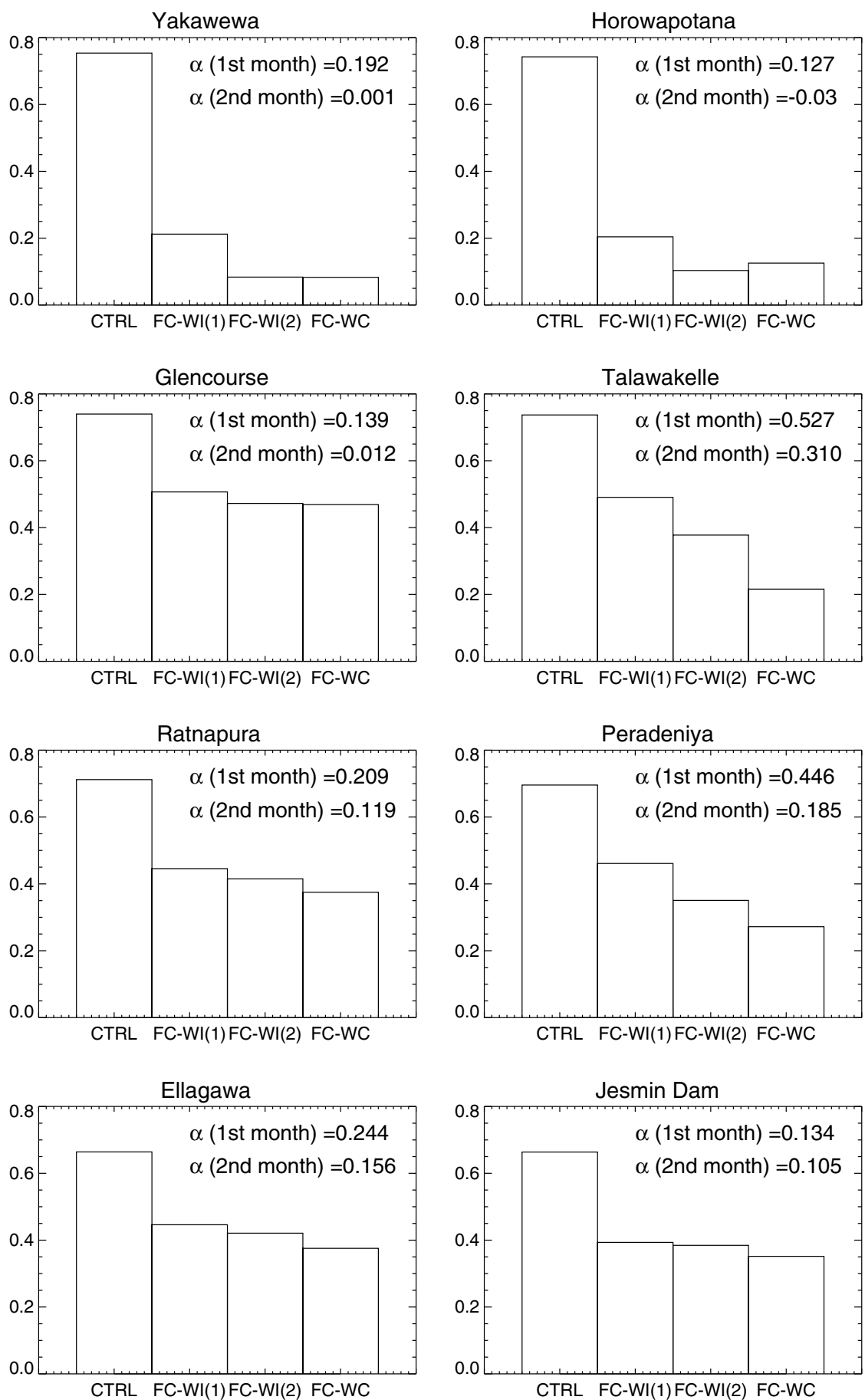

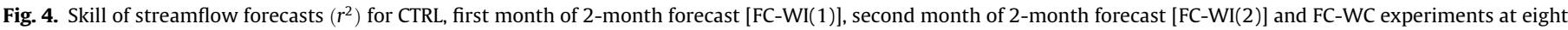
watersheds. Corresponding $\alpha$ values are written on each panel. 
The interior bars show the forecast skill resulting from realistic soil moisture initialization for 1-day, 5-day, and 10-day streamflow forecasts, when these forecasts are summed to monthly totals. As expected, the forecast skill associated with soil moisture initialization decreases with increasing lead. Notice, however, that the inferred skill for the 1-day forecasts is quite high, almost the same as that for CTRL. This is particularly true in the wetter catchments, reflecting, at least in part, the fact that much of the streamflow generated in these catchments comes from baseflow, which is a direct function of soil moisture rather than of incident precipitation. In other words, because baseflow does not depend directly on incident precipitation, the "predicted" precipitation could be quite wrong and the runoff would still be close to that in CTRL. As the
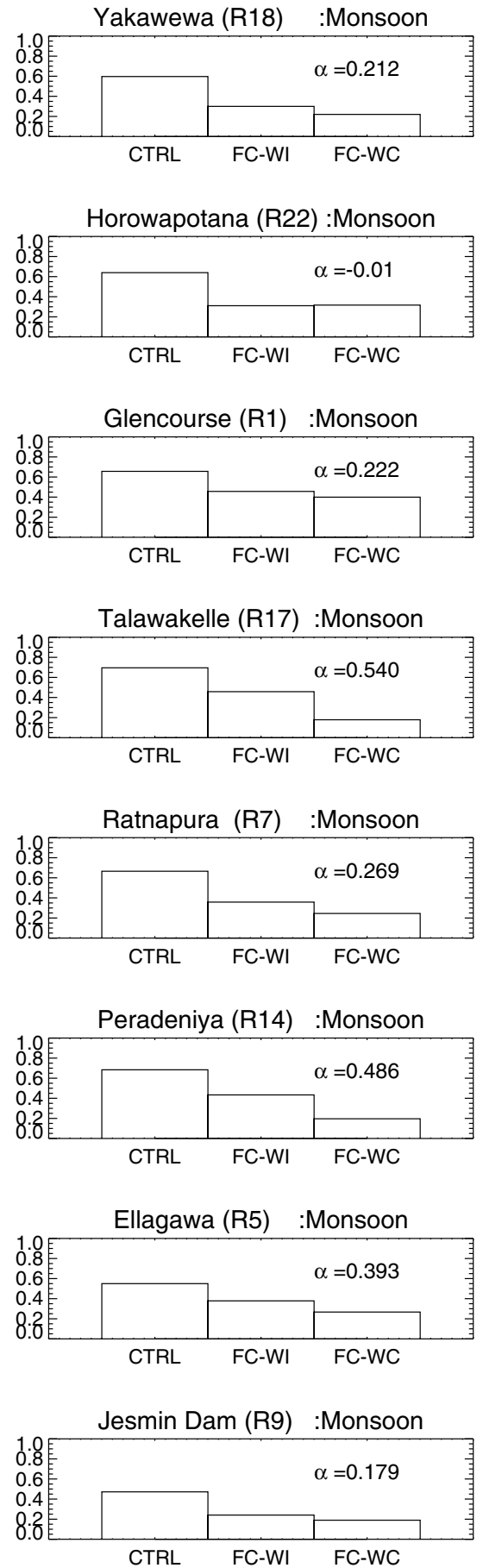

lead increases to 10 days, the effect of the poorly predicted precipitation on the total soil moisture (and thus on baseflow) becomes larger, and the skill is reduced. Again, we are unable here to perform a direct evaluation of streamflow prediction at these shorter timescales. Nevertheless, from this indirect analysis, we can infer that soil moisture initialization adds a substantial amount of skill to streamflow prediction at submonthly leads.

\subsection{Implications for streamflow prediction across Sri Lanka}

Based on the significant skill levels associated with land moisture initialization in Figs. 4 and 5, we make the (otherwise unsupported) assumption here that the model and forcing observations
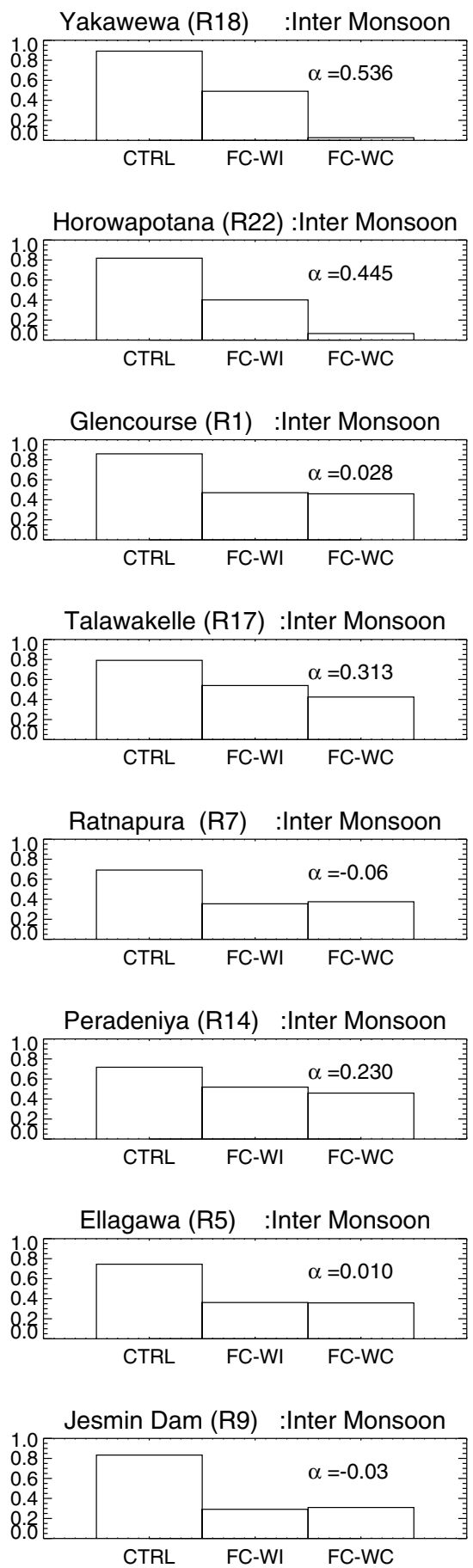

Fig. 5. Breakdown analysis of Fig. 4 by monsoon and inter-monsoon seasons (for the first month of forecast). 
are adequate for a general analysis of soil moisture initialization impact on streamflow across Sri Lanka, not just at the eight examined sites. The nationwide analysis gives a broad, if approximate, overview of how soil moisture affects streamflow prediction as a function of season and geographical location.

Because we do not have streamflow measurements across Sri Lanka to compute spatial distributions of $r^{2}$ values, we instead computed cross correlations between soil moisture on a given day and simulated monthly runoff fraction (with a lag time of 13 months) following that day. The seasonal cycles of the data were removed prior to the calculations. Fig. 7 shows the correlation coefficient ( $r$, essentially the cross correlation between anomalies) between the soil moisture on a given day and the simulated runoff fraction during the first month (first column), the second month (second column) and the third month (third column) following that day, for each of the four seasons (one season per row), as computed in CTRL. (The particular days of soil moisture examined were indeed the first days of each month.) Again, we are assuming here that the model captures, to first order, the impact of soil moisture memory on streamflow production. For the first month, correlations are high (and statistically significant at a 95\% confidence level, though see the caveat below) across most of the island, particularly during AMJ and JAS. For months 2 and 3, no significant correlations exist for JFM, and almost none exist for OND. Across
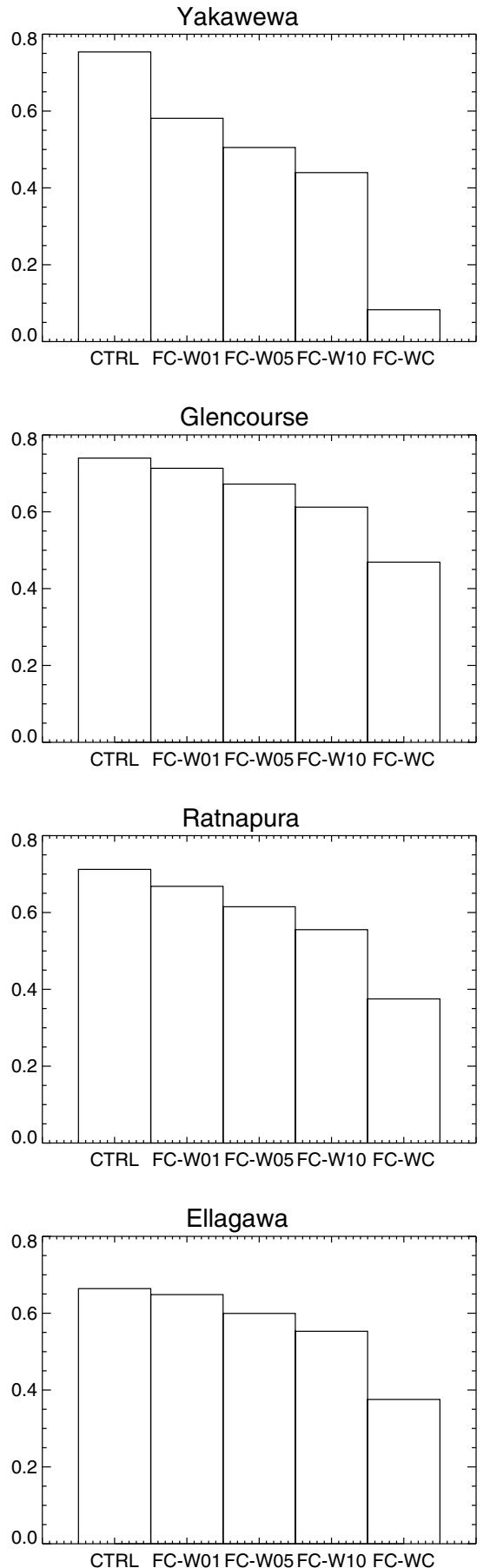
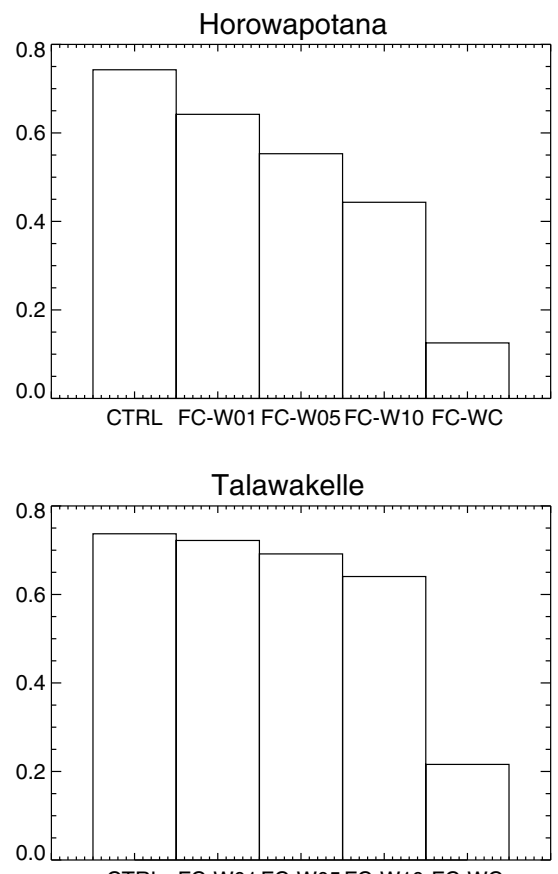

CTRL FC-W01FC-W05FC-W10 FC-WC
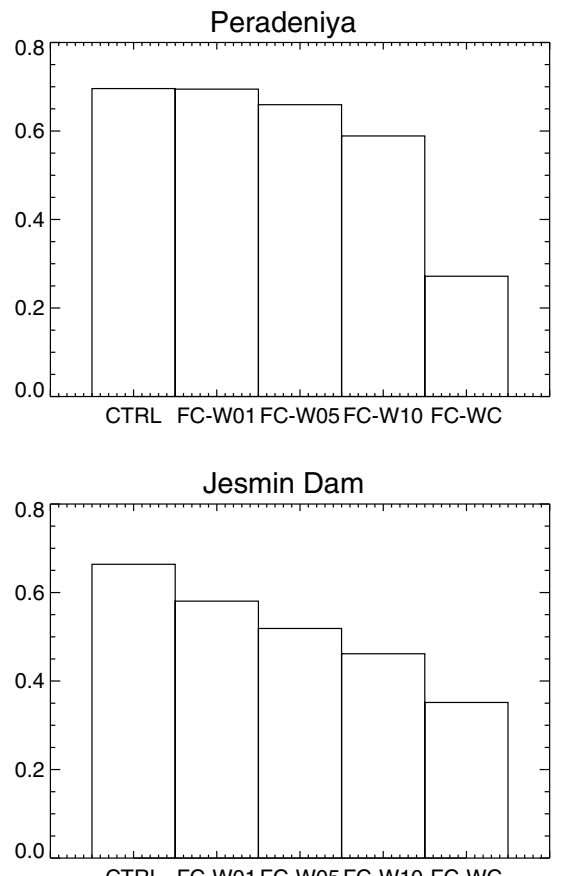

Fig. 6. Skill of forecast at sub-monthly timescale: $r^{2}$ values for CTRL, FC-W01, FC-W05, FC-W10, and FC-WC experiments 
the island, correlations remain large for months 2 and 3 for AM] and JAS. Perhaps these are the seasons for which useful streamflow prediction in Sri Lanka is most achievable.

The areal extents of the statistically significant local correlations shown in Fig. 7 may, however, be overestimated, given large-scale spatial correlations in the soil moisture and runoff fields. A superior significance analysis would not consider the catchment products in isolation. To avoid this problem - to determine, to first order, the lags and seasons showing significant correlations for Sri Lanka as a whole - we computed cross correlations between island-wide average soil moisture anomalies and islandwide runoff fraction anomalies, for each season and each lead time separately. The island-wide cross correlation (IWC) values are provided inside each panel in Fig. 7. Island-wide statistically significant correlations are seen for AMJ at all three leads. (Note the 95\% confidence level applicable here is 0.3 , based on Monte Carlo techniques.) The island-wide values are not significant in other seasons.

\section{Discussion and summary}

While both soil moisture initialization and accurate precipitation forecasts can contribute to accurate streamflow forecasts, realistic soil moisture initialization is generally far more achievable
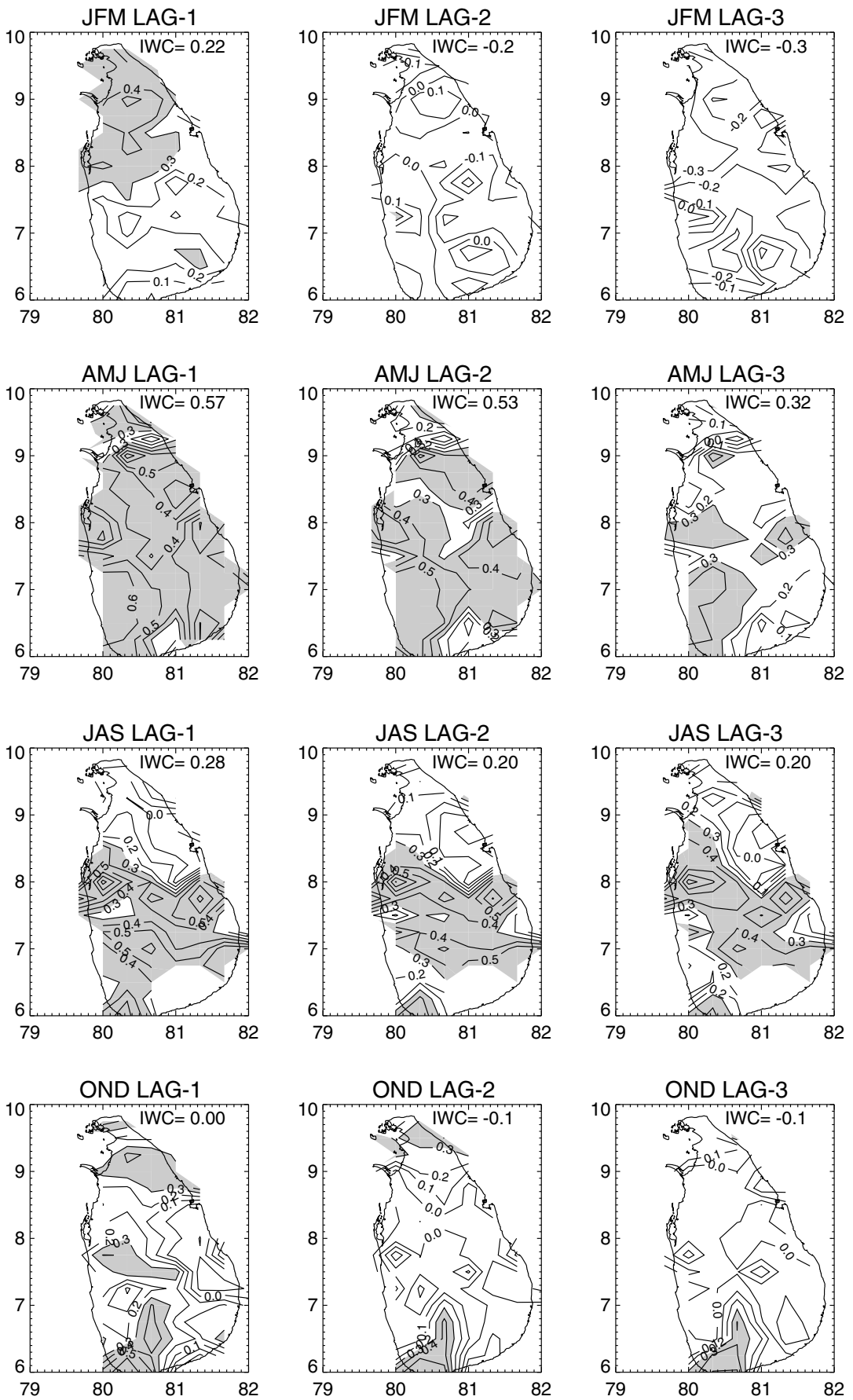

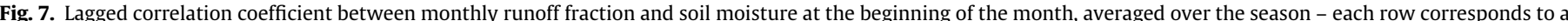

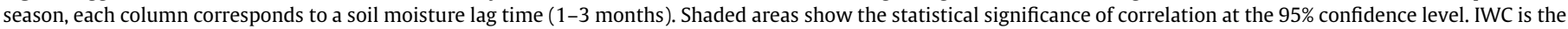
island-wide correlation (see text for details). 
(through real-time land data analysis) than is the accurate prediction of precipitation. Here, we examine the relative contribution of soil moisture initialization to the skill of streamflow forecasts in several watersheds on the tropical island of Sri Lanka. Gridded reanalysis-based surface meteorological forcings were merged with gridded observed precipitation measurements to produce a meteorological forcing dataset used to drive the Catchment LSM in offline mode, thereby producing simulated runoff and soil moisture at the catchment scale across the island. Monthly streamflow measurements from 22 watersheds, located at different altitudes and in various climatic settings, provided the data to evaluate model performance. The streamflow variations were, in general, reasonably simulated. Computed $r^{2}$ values between the simulated and observed monthly runoff at the 22 stations varied from 0.23 to 0.75 . For our further analyses (looking at streamflow prediction at timescales ranging from 1 day to 2 months), we focused on the eight stations for which the land model is found to perform particularly well, i.e., the eight stations for which the $r^{2}$ values between simulated and observed runoff are greater than 0.66 .

The study shows that the contribution of the initial soil moisture state to monthly streamflow forecast skill is about $10-60 \%$ of that achieved via both initialization and the "perfect" prediction of precipitation (and other meteorological forcing) over the month. The contribution is reduced to $0 \%-30 \%$ for the second month of the forecast. Because a perfect prediction of atmospheric forcing is impossible to achieve in practice, the relative contribution of realistic soil moisture initialization to achievable streamflow forecast skill is necessarily higher. Analysis of shorter forecast leads (submonthly) shows the expected increase in the relative contribution as the lead time decreases. For drier catchments, soil moisture initialization appears to have a stronger impact on streamflow forecast skill during inter-monsoon seasons, whereas in wetter catchments, the opposite appears to be true.

An island-wide study of soil moisture as a predictor in streamflow forecasts was then performed. Streamflow during AMJ is particularly well correlated with earlier soil moisture (lag up to 3 months), suggesting that this may be the season for which streamflow in Sri Lanka as a whole is most predictable.

Overall, our results indicate that accurate soil moisture initialization can contribute to the generation of useful streamflow predictions. The forecast skill could, of course, be further improved if the model's formulations were improved. The simulation framework used here can perhaps also serve as a valuable tool for risk assessment studies on floods, landslides and malaria. Flood and landslide risk are affected by soil moisture and/or the associated streamflow, and malaria risk is sensitive to both pool formation (for which saturated area, an output variable of CLSM, is a good proxy) and streamflow extremes.

\section{Acknowledgements}

We thank the Sri Lanka Department of Meteorology, Irrigation and Mahaweli Authority of Sri Lanka for assisting with data. The observed data were pre-processed at Foundation for Environment Climate and Technology, Digana Village, Sri Lanka. The authors would like to thank Dr. Andrew Wood and two anonymous reviewers for the insightful comments which helped improve the manuscript.

\section{References}

[1] Wood AW, Maurer EP, Kumar A, Lettenmaier DP. Long range experimental hydrologic forecasting for the eastern US. J Geophys Res 2002;107:4429. doi:10.1029/2001JD000659.

[2] Wood AW, Kumar A, Lettenmaier DP. A retrospective assessment of NCEP climate model-based ensemble hydrologic forecasting in the western US. J Geophys Res 2005;110:4105. doi:10:1029/2004JD004508.
[3] Wood AW, Lettenmaier DP. Test bed for new seasonal hydrologic forecasting approaches in the western United States. Bull Am Meteor Soc 2007;87(12):1699-712. doi:10.1175/BAMS-87-12-1699.

[4] Vintzileos A, Rienecker MM, Suarez MJ, Miller SK, Pegion PJ, Bacmeister JT. Simulation of the El Nino-Southern Oscillation phenomenon with NASAs seasonal-to-interannual prediction project coupled general circulation model. CLIVAR Exch 2003;8:25-7.

[5] Goddard L, Mason SJ, Zebiak SE, Ropelewski CF, Basher R, Cane MA. Current approaches to seasonal-to-interannual climate predictions. Int J Climatol 2001;21:1111-52.

[6] Suppiah R. Extremes of the southern oscillation phenomenon and the rainfall of Sri Lanka. Int J Climatol 1997;17:87-101.

[7] Chandimala J, Zubair L. Predictability of streamflow and rainfall for water resources management in Sri Lanka. J Hydrol 2007;335(3-4):303-12.

[8] Leung LR, Hamlet AF, Lettenmaier DP, Kumar A. Simulations of the ENSO hydroclimate signals in the Pacific Northwest Columbia River basin. Bull Am Meteor Soc 1999;80(11):2313-29.

[9] Maurer EP, Lettenmaier DP. Predictability of seasonal runoff in the Mississippi River basin. J Geophys Res 2003;108(D16):8607. doi:10.1029/2002JD002555.

[10] Berg AA, Mulroy KA. Streamflow predictability in the Saskatchewan/Nelson River basin given macroscale estimates of the initial soil moisture status. Hydrol Sci 2006;51(4):642-54.

[11] Wood AW, Lettenmaier DP. An ensemble approach for attribution of hydrologic prediction uncertainty. Geophys Res Lett, in press. doi:10.1029/ 2008GL034648.

[12] Zehe E, Blöschl G. Predictability of hydrologic response at the plot and catchment scales: role of initial conditions. Water Resour Res 2004;40:W10202. doi:10.1029/2003WR002869.

[13] Entin JK, Robock A, Vinnikov KY, Hollinger SE, Liu S, Namkhai A. Temporal and spatial scales of observed soil moisture variations in the extratropics. J Geophys Res 2000;105(D9):11865-77.

[14] Vinnikov K, Ya A, Robock N, Speranskaya A, Schlosser A. Scales of temporal and spatial variability of midlatitude soil moisture. J Geophys Res 1996;101(D3):7163-74.

[15] Rodell M, Houser PR, Jambor U, Gottschalck J, Mitchell K, Meng C-J, et al. The global land data assimilation system. Bull Am Meteor Soc 2004;85(3):381-94.

[16] Reichle RH, Koster RD, Liu P, Mahanama SPP, Njoku EG, Owe M. Comparison and assimilation of global soil moisture retrievals from the advanced microwave scanning radiometer for the earth observing system (AMSR-E) and the scanning multichannel microwave radiometer (SMMR). J Geophys Res 2007;112(D09108). doi:10.1029/2006JD008033.

[17] Rienecker MM, Suarez MJ, Koster RD, Reichle RH, Keppenne C, Adamec D, et al. Improving short-term climate forecasts with satellite observations. Invited Presentation at IGARSS, Denver (CO) USA; 2006.

[18] Arumugam S. Water resources of Ceylon its utilization and development Water Resources Board Publications, Colombo, Sri Lanka; 1969. 415p.

[19] Zubair L. Weather and climate of Sri Lanka and impacts and adaptation: a reference guide. Natural Resources Management Services; 2004. 116p. ISBN: 955-8968-00-5.

[20] Koster RD, Milly PCD. The interplay between transpiration and runoff formulations in land surface schemes used with atmospheric models. J Climate 1997;10:1578-91.

[21] Koster RD, Suarez MJ, Ducharne A, Stieglitz M, Kumar P. A catchment-based approach to modeling land surface processes in a general circulation model. (1) Model structure. J Geophys Res 2000;105(D20):24809-22.

[22] Ducharne A, Koster RD, Suarez MJ, Stieglitz AM, Kumar P. A catchment-based approach to modeling land surface processes in a general circulation model. (2) Parameter estimation and model demonstration. J Geophys Res 2000;105(D20):24823-38.

[23] Bowling LC, Lettenmaier Dennis P, Nijssen Bart, et al. Simulation of high latitude hydrological processes in the Torne-Kalix basin: PILPS Phase $2 \mathrm{e} 1$ : experiment description and summary intercomparisons. Global Planetary Change 2003;38:1-30.

[24] Nijssen B, Bowling Laura C, Lettenmaier Dennis P, et al. Simulation of high latitude hydrological processes in the Torne-Kalix basin: PILPS Phase $2 \mathrm{e} 2$ : comparison of model results with observations. Global Planetary Change 2003;38:31-53.

[25] Boone A, Habets F, Noilhan J, Clark D, Dirmeyer P, Fox S, et al. The Rhoneaggregation land surface scheme intercomparison project: an overview. J Climate 2004;17(1):187-208.

[26] Seneviratne SI, Koster RD, Guo Z, Dirmeyer PA, Kowalczyk E, Lawrence D, et al. Soil moisture memory in AGCM simulations: analysis of global landatmosphere coupling experiment (GLACE) data. J Hydrometeor 2006;7:1090-112.

[27] Mahanama SPP, Koster RD. Intercomparison of soil moisture memory in two land surface models. J Hydrometeor 2003;4:1134-46.

[28] Belward AS, Estes JE, Kline KD. The IGBP-DIS 1-km land-cover data set DISCover: a project overview. Photogram Eng Remote Sens 1999;65(9): 1013-20.

[29] Reynolds CA, Jackson TJ, Rawls WJ. Estimating available water content by linking the FAO soil map of the world with global soil profile databases and Pedo-transfer functions. In: Proceedings of the AGU 1999 spring conference, Boston (MA); May 31-June 4.

[30] Berg AA, Famiglietti JS, Rodell M, Reichle RH, Jambor U, Holl SL, et al. Development of a hydrometeorological forcing data set for global soil moisture estimation. Int J Climatol 2005;13:1697-714. 
[31] Mitchell KE, Lohmann D, Houser PR, Wood EF, Schaake JC, Robock A, et al. The multi-institution North American land data assimilation system (NLDAS): utilizing multiple GCIP products and partners in a continental distributed hydrological modeling system. J Geophys Res 2004;109(D07S90). doi:10.1029/ 2003JD003823.

[32] Dirmeyer PA, Guo Z, Gao X. Validation and forecast applicability of multi-year global soil wetness products. J Hydrometeor 2004;5:1011-33.
[33] Mahanama SPP, Koster RD. AGCM biases in evaporation regime: impact on soil moisture memory and land-atmosphere feedback. J Hydrometeor 2005;6(5):656-69.

[34] Pulaneswaran KM, Smithson PA. An objective classification of homogeneous rainfall regimes in Sri Lanka. Theor Appl Climatol 1993;48:133-45. 